\title{
Design of a direct-detection wind and aerosol lidar for mars orbit
}

\author{
Daniel R. Cremons ${ }^{1}(\mathbb{D})$ James B. Abshire ${ }^{1,2} \cdot$ Xiaoli Sun $^{1} \cdot$ Graham Allan $^{1,3} \cdot$ Haris Riris $^{1} \cdot$ Michael D. Smith ${ }^{1}$. \\ Scott Guzewich ${ }^{1}$. Anthony Yu ${ }^{1}$. Floyd Hovis ${ }^{4}$
}

Received: 10 April 2019 / Revised: 31 January 2020 / Accepted: 2 February 2020 / Published online: 17 February 2020

(c) The Author(s) 2020

\begin{abstract}
The present knowledge of the Mars atmosphere is greatly limited by a lack of global measurements of winds and aerosols. Hence, measurements of height-resolved wind and aerosol profiles are a priority for new Mars orbiting missions. We have designed a direct-detection lidar (MARLI) to provide global measurements of dust, winds and water ice profiles from Mars orbit. From a 400-km polar orbit, the instrument is designed to provide wind and backscatter measurements with a vertical resolution of $2 \mathrm{~km}$ and with resolution of $2^{\circ}$ in latitude along track. The instrument uses a single-frequency, seeded Nd:YAG laser that emits $4 \mathrm{~mJ}$ pulses at $1064 \mathrm{~nm}$ at a $250 \mathrm{~Hz}$ pulse rate. The receiver utilizes a 50-cm diameter telescope and a doubleedge Fabry-Pérot etalon as a frequency discriminator to measure the Doppler shift of the aerosol-backscatter profiles. The receiver also includes a polarization-sensitive channel to detect the cross-polarized backscatter profiles from water ice. The receiver uses a sensitive $4 \times 4$ pixel $\mathrm{HgCdTe}$ avalanche photodiode array as a detector for all signals. Here we describe the measurement concept, instrument design, and calculate its performance for several cases of Mars atmospheric conditions. The calculations show that under a range of atmospheric conditions MARLI is capable of measuring wind speed profiles with random error of $2-4 \mathrm{~m} / \mathrm{s}$ within the first three scale heights, enabling vertically resolved mapping of transport processes in this important region of the atmosphere.
\end{abstract}

Keywords Mars $\cdot$ Lidar $\cdot$ Wind $\cdot$ Doppler $\cdot$ Remote sensing $\cdot$ Aerosol

\section{Introduction}

Previous space-based measurements [1-5] and modeling $[6,7]$ have been used to study Mars atmospheric processes. Observations show that the main variability in the present Mars climate is related to variations in the spatial and temporal distribution of dust and water ice aerosols $[8,9]$. Dust interacts strongly with infrared radiation, which leads to changes in the thermal structure and acts as a driver of atmospheric motions at all spatial scales [10]. Water ice clouds play an important role in the water cycle altering the global transport of water vapor, including to active surface briny water flows (i.e., recurring slope lineae) $[11,12]$. The

Daniel R. Cremons

daniel.cremons@nasa.gov

NASA Goddard Space Flight Center, Greenbelt, MD, USA

University of Maryland, College Park, MD, USA

Sigma Space Corp., Lanham, MD, USA

4 Fibertek Inc., Herndon, VA, USA vertical distributions of dust and water ice aerosols exhibit complex structures that are not well-understood [13, 14]. Observations using imaging and spectroscopic instruments on Mars orbiters [13, 15-19] have shown a wide variety of unexpected behavior including detached clouds, inversions in aerosol vertical profiles and very high altitude clouds. New measurements of the diurnal variations of aerosols, water vapor abundance, and winds [20,21] are still required to answer some important questions.

Despite low atmospheric density, the winds are often strong enough to raise large amounts of dust from the surface, and at times the planet can become almost completely enshrouded in it (see [16, 22] for one such example). The winds transport water vapor, dust and ice aerosols, and mix all atmospheric gaseous constituents. Wind erodes the surface to create dust and sand particles and then transports these aeolian deposits, reshaping the surface geology. Winds regulate the transfer of water vapor and heat throughout the atmosphere and are a primary player in all surface-atmosphere interactions. Wind velocities provide sensitive input and validation for Global Circulation Models (GCMs), and 
are important for the safety and precision of spacecraft entry, descent and landing (EDL). Finally, Mars weather and wind predictions are important since dust storms and high winds affect mission operations on the surface that require visibility and consistent solar irradiation [16, 23, 24].

Despite their importance, there are very few direct observations of Mars winds. Current knowledge relies on a few cloud and wind streak observations, isolated observations from the Viking and Mars Science Laboratory landers [25, 26], and indirect inferences of wind speeds that are often imprecise and contain many assumptions (e.g., [27]). The ability to sample wind profiles globally at all times of day and throughout seasons will also directly address science goals relating to the water cycle $[11,12,28]$. In addition to present day atmospheric processes, comparison of current wind values with recent and varying aeolian features will yield information on formation mechanisms, rates of change, and historical wind trends [30-32]. The 2011 Planetary Science Decadal Survey and the Mars Exploration Program Analysis Group (MEPAG) Goals Documents have cited several investigation aims that would be directly addressed by aerosol and wind measurements from orbit [21, 33], and knowledge of winds remains a key "knowledge gap" for future human exploration of Mars.

\section{Lidar Overview}

We have designed a direct-detection Doppler wind lidar for Mars orbit (MARLI) to address these needs. It is designed to provide vertically-resolved profiles of dust, water ice, and line-of-sight (LOS) winds to the surface, globally in all seasons day and night [34-38]. MARLI is designed to operate from a spacecraft in a circular polar orbit at a nominal altitude of $400 \mathrm{~km}$. MARLI will be pointed $30^{\circ}$ off-nadir in the cross-track direction, allowing for retrieval of cross-track wind profiles as shown in Fig. 1.

A block diagram of the instrument design is shown in Fig. 2. The lidar transmitter is a frequency-locked, diodepumped Nd: YAG laser that emits optically polarized pulses at $1064 \mathrm{~nm}$. The MARLI receiver measures the verticallyresolved aerosol scattering profiles in the same polarization, as well the backscatter profiles that are cross-polarized. The parallel polarized backscatter profiles are passed through a solid, fused-silica Fabry-Pérot etalon used as a frequency discriminator, and their Doppler shifts are measured via the double-edge Fabry-Pérot lidar technique [39-41].

The present layout of the MARLI lidar is shown in Fig. 3. The current estimates of instrument payload parameters are a mass of $36 \mathrm{~kg}$, operating power of $81 \mathrm{~W}$, and data rate of $50 \mathrm{kbit} / \mathrm{s}$. These parameters are nominal and were derived from the prototype versions of the laser, telescope, receiver optics, and detector.

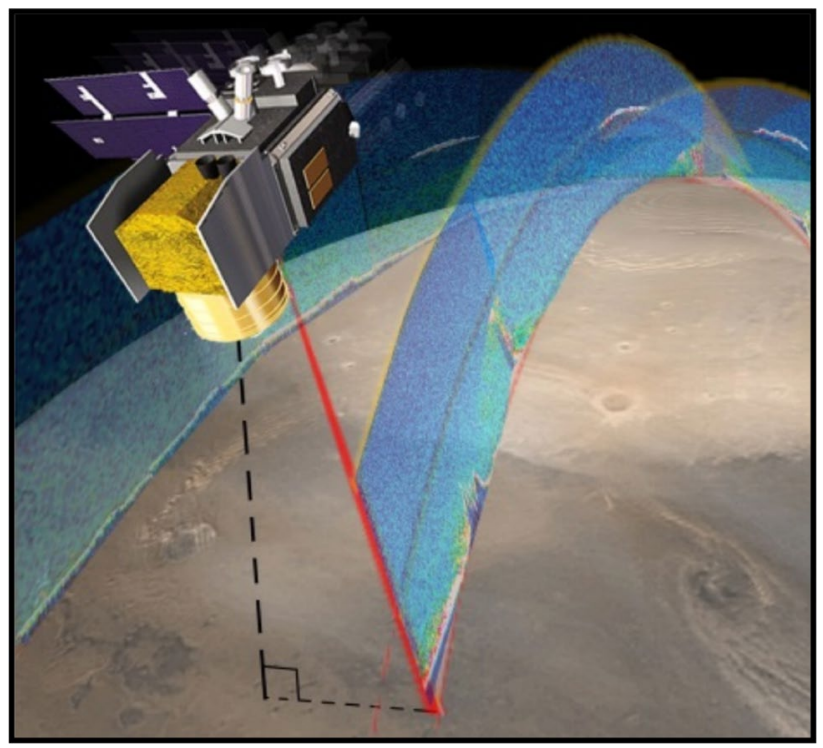

Fig. 1 MARLI measurement concept. The lidar is pointed $30^{\circ}$ offnadir in the cross-track direction

In the remaining sections we describe the MARLI Doppler and polarization measurement approaches. Next, we provide a description of the major elements of the prototype instrument and discuss our method of determining the laser frequency and Doppler accuracy. We then present Mars atmospheric conditions from measurements taken by the Mars Climate Sounder used to calculate the expected instrument performance. Finally, we present a lidar model and estimate the measurement performance. We also briefly discuss our ongoing work to mature the technical readiness of the MARLI instrument to prepare for its consideration for a space mission.

\section{Measurement approach}

In orbit the MARLI instrument is designed to be nominally pointed at $30^{\circ}$ from nadir in the cross-track direction. Its laser emits stable narrow linewidth laser pulses at a $250 \mathrm{~Hz}$ rate. The lidar receiver measures range-resolved backscatter profiles of the Mars atmosphere in three channels. The MARLI transmitted laser pulses are highly polarized (100:1). Two of the receiver channels measure the parallelpolarized backscatter but their passbands in frequency are slightly offset from one another to resolve the Doppler shift caused by wind-blown aerosols. The third channel measures the cross-polarized laser backscatter and is not Doppler resolved. The cross-polarized profiles can be used to detect and profile scattering from ice crystals that form clouds on Mars [42, 43].

The laser photons that are scattered by aerosols back toward the lidar undergo a frequency shift due to the Doppler 
Fig. 2 Block diagram of the MARLI lidar

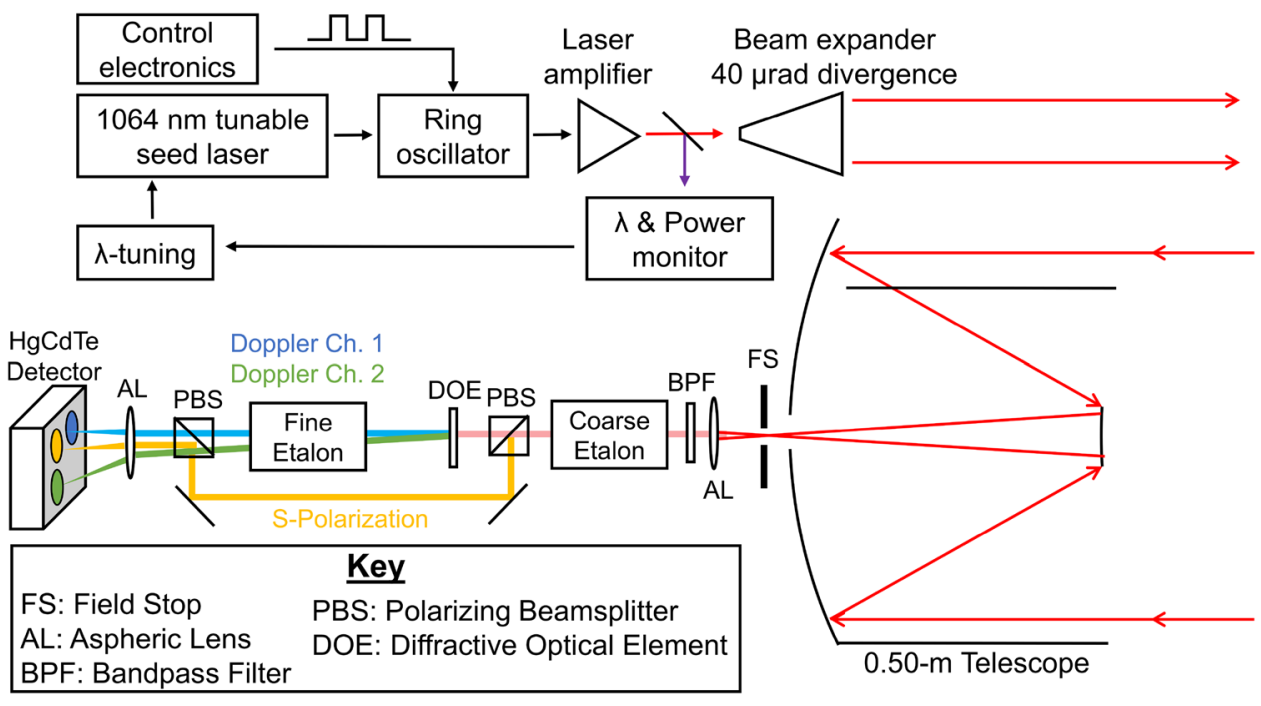

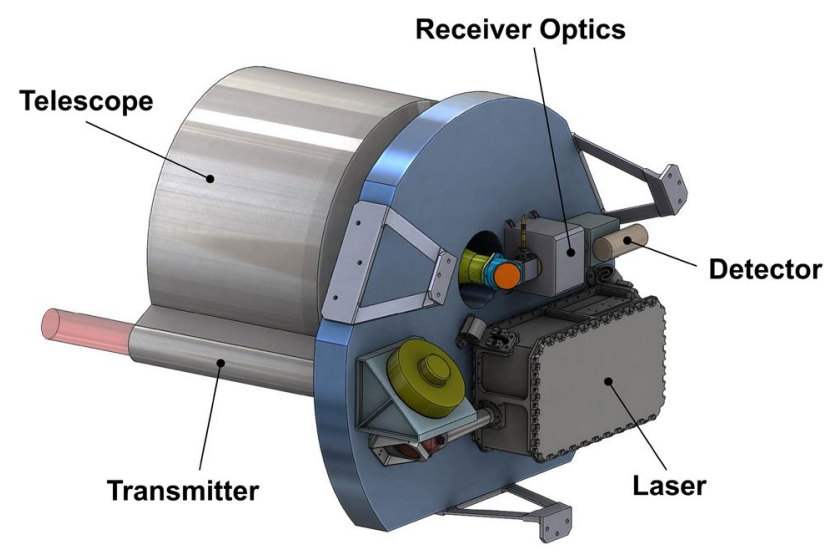

Fig. 3 Present MARLI flight-instrument concept. The receiver telescope is $50 \mathrm{~cm}$ in diameter

effect. The frequency shift is given by $\Delta f=2 \cdot f_{0} V_{\mathrm{LOS}} / c$, where $f_{0}$ is the transmitted laser photon frequency, $V_{\mathrm{LOS}}$ is the wind velocity in the line-of-sight direction and $c$ is the speed of light. At the MARLI laser frequency of $281.759 \mathrm{THz}$ $(1064 \mathrm{~nm})$ the resulting frequency shift for a $1 \mathrm{~m} / \mathrm{s} \mathrm{LOS}$ wind speed is $1.8 \mathrm{MHz}$. At $1064 \mathrm{~nm}$ the low atmospheric pressure of Mars ( $7 \mathrm{hPa}$ at the surface) causes very little Rayleigh scatter and the ratio of aerosol to Rayleigh scatter is $\sim 2000$ or greater. This allows MARLI to use the stronger $\mathrm{Nd}$ :YAG laser emission at $1064 \mathrm{~nm}$, in contrast with lidar approaches for measuring winds in Earth's atmosphere that use the second $(532 \mathrm{~nm})$ or third harmonic $(354.7 \mathrm{~nm})$ wavelengths $[44,45]$.

Historically several types of spectral filters have been used in direct detection Doppler lidar receivers, including approaches based on etalons, absorption lines [46], Fizeau interferometers [47], fringe imaging [48], and
Mach-Zehnder interferometers [49, 50]. The MARLI optical receiver uses a frequency discriminator based on the double-edge Fabry-Pérot etalon (DEFP) technique [40, 51-53]. Using a single edge technique, high measurement sensitivity of the LOS aerosol motion was achieved using the edge of a spectral filter [41]. The use of a second filter edge (i.e. double-edge) increases the measurement sensitivity resulting in a 1.6-times improvement in the measurement accuracy [40]. The double-edge technique involves locking the laser frequency at the crossing point (i.e. the half-widths) of two filter edges of opposite slope and measuring the changes in signal through the two filters simultaneously. We chose the DEFP technique with a solid etalon for MARLI due to its simplicity, ruggedness, and its compatibility with the number of pixels available in the lidar detector.

In the MARLI receiver design a single etalon is used for both edge filters, similar to the design described by Kim et al. [54]. Briefly, the laser backscatter that is collected by the receiver telescope is split into two paths, which are directed through a solid, fused silica Fabry-Pérot etalon at two slightly different angles. One of the paths is normally incident on the etalon front surface while the other is offset by $1.2 \mathrm{mrad}$. After passing through the etalon both paths illuminate separate detector elements. This angular offset shifts the optical passband frequency for the offset path, and both paths together form a simple double-edge frequency discriminator. When the laser frequency is locked to the crossing point of the two filters the zero-Doppler-shift point is at the maximum slopes of the two passbands. With an etalon, the angular offset of the second path causes a slightly lower transmittance and slightly broader, asymmetrical bandwidth for that path, which does slightly degrade the measurement precision [55]. 


\section{Lidar component description}

The prototype laser transmitter was designed and constructed by Fibertek, Inc. and leveraged some elements of an earlier laser design used in the Cloud-Aerosol Transport System lidar [56]. The Nd:YAG laser is a Q-switched master-oscillator power-amplifier (MOPA) design using a tunable single frequency seed laser, a ring oscillator, and a single stage power amplifier.

The MARLI laser requires a low power single frequency laser to seed the laser's ring oscillator in order to maintain a stable single frequency emission. Our approach uses a micro-non-planar ring oscillator ( $\mu$ NPRO) that is being developing for the Laser Interferometer Space Antenna (LISA) mission [57]. The $\mu$ NPRO allows higher power and narrower, and much more stable linewidth than a diode seed laser in a small, efficient package. The present $\mu$ NPRO layout is shown in Fig. 4.

Figure 5 shows the layout of the laser transmitter with optics and the amplifier on the front face, and the electronics and laser output on the opposite face, along with the single cold plate for connection to an external heat pipe or liquid cooling plate. The laser parameters are listed in Table 1 along with specifications for the telescope, receiver optics, and detector.

The lidar receiver uses a Cassegrain telescope made of beryllium that has a $50-\mathrm{cm}$ diameter and a $2-\mathrm{m}$ effective focal length. The telescope optical surfaces are gold coated with a sunshield surrounding the primary mirror that may also be used as a thermal radiator. From the field stop, the received light is recollimated to a beam diameter of $50 \mathrm{~mm}$ to fill the etalon's clear aperture. The received photons then pass through the spectral filter assembly, which includes (in series) a bandpass filter, a gapped etalon, a diffractive optical element (DOE), and the fused-silica (fine) etalon that forms

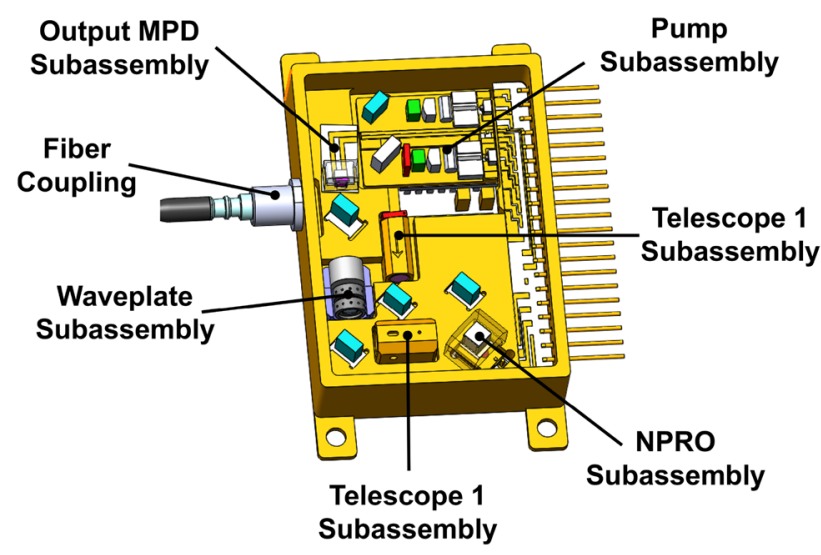

Fig. 4 Layout drawing for the $\mu$ NPRO seed laser package and optical bench. The approximate dimensions are $5 \mathrm{~cm}$ by $6 \mathrm{~cm}$ by $1 \mathrm{~cm}$

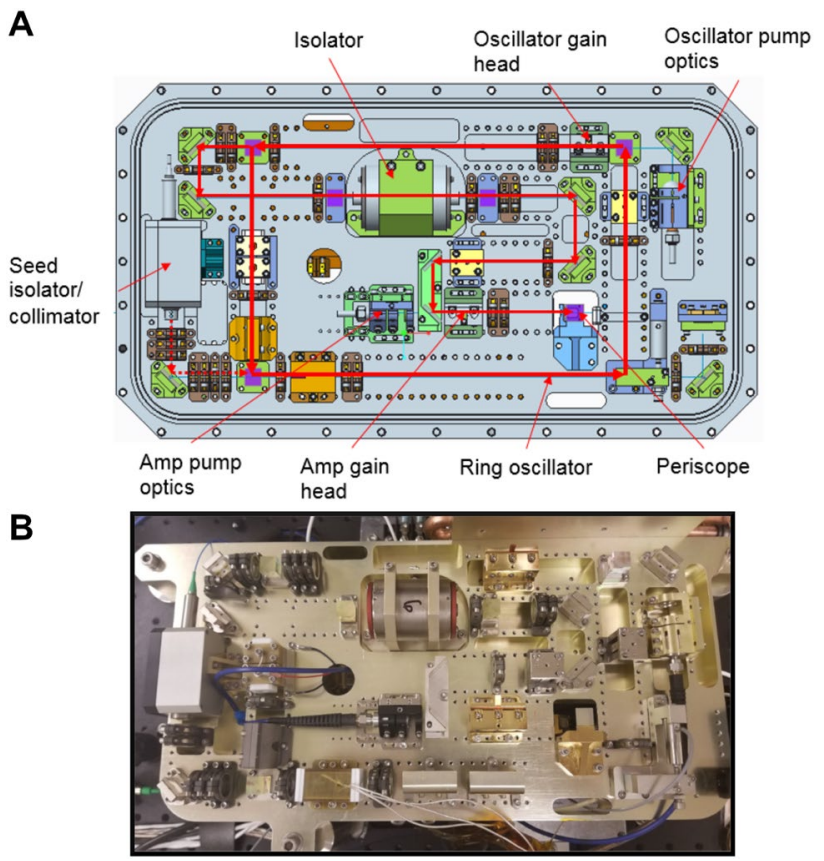

Fig. 5 Two views of the MARLI laser optical bench. a A layout drawing of the laser's optical bench. The red line traces the laser beam path from the seed on the left-hand side through to the periscope on the right lower section, after which the beam is expanded before exiting the laser on the back face. b A photograph of the same side of the as-built laser prototype during assembly from the same viewpoint. The approximate dimensions are $40 \mathrm{~cm}$ by $22 \mathrm{~cm}$ by 15 $\mathrm{cm}$. The seed laser stage is not shown

the double-edge filter. Plots of the frequency-dependent transmission of each element in the serial filter stack are shown in Fig. 6.

The bandpass filter (black curve in Fig. 6a-c) blocks most of the solar background. Its transmission peak was designed to be sufficiently narrow to block all but one passband of the coarse etalon (green curve). Although five resonance peaks of the fine etalon are contained within the FWHM of the coarse etalon bandwidth (Fig. 6b), this configuration allows sufficient optical transmission at the laser wavelength while also minimizing the daytime optical background to the detector. The cumulative transmission losses of the three elements combined with locking the frequency to the edge of the fine etalon at the half-width point results in an overall filter stack transmission of $32 \%$ for each of the double-edge Doppler channels.

After the coarse etalon the optical signal passes through a polarizing beamsplitter (PBS). It reflects parallel-polarized light towards the DOE and the double-edge filter, while the perpendicularly-polarized light is transmitted through the PBS towards a second optical path that bypasses these elements. The linear depolarization ratio of the backscattered profile can be calculated from the measurements of the signal through each of the edge filter channels 
Table 1 Parameters for the MARLI lidar

\begin{tabular}{|c|c|c|c|c|c|}
\hline Laser & \multicolumn{3}{|c|}{ Receiver telescope } & \multicolumn{2}{|l|}{ Receiver double edge etalon } \\
\hline Wavelength & $1064.48 \mathrm{~nm}$ & Type & Cassegrain & Material & Fused silica \\
\hline Laser line width (FWHM) & $30 \mathrm{MHz}$ & Diameter & $50 \mathrm{~cm}$ & Surface reflectance & $88.20 \%$ \\
\hline Laser divergence & $375 \mu \mathrm{rad}$ & Field of view & $60 \mu \mathrm{rad}$ & Index of refraction, $n_{\mathrm{E}}$ & 1.45 \\
\hline Pulse duration & $28 \mathrm{~ns}$ & Material & Beryllium & Free spectral range, $F_{\lambda}$ & $2.59 \mathrm{GHz}$ \\
\hline Pulse repetition rate & $250 \mathrm{~Hz}$ & Coating & Gold & Finesse, $\mathscr{F}$ & 25 \\
\hline Energy per pulse & $4-5 \mathrm{~mJ}$ & \multicolumn{2}{|l|}{ Receiver optical bandpass filter } & Diameter & $60 \mathrm{~mm}$ \\
\hline Polarization purity & $100: 1$ & Passband FWHM & $1.072 \mathrm{~nm} / 283.7 \mathrm{GHz}$ & Clear aperture & $50 \mathrm{~mm}$ \\
\hline Sideband suppression & $23 \mathrm{~dB}$ & Peak transmission & $98.65 \%$ & Input beam divergence & $<0.7 \mathrm{mrad}$ \\
\hline Output beam divergence & $40 \mu \mathrm{rad}$ & Receiver coarse etalon & & Peak transmission, $\eta_{\mathrm{pk}}$ & $70 \%$ \\
\hline Frequency stability & $5 \mathrm{MHz} / 30 \mathrm{~min}$ & Plate spacing & $0.428 \mathrm{~mm}$ & Absorption & $1.90 \%$ \\
\hline Output beam diameter & $5.2 \mathrm{~cm}$ & Fabry-Pérot FSR & $1323 \mathrm{pm} / 350.1 \mathrm{GHz}$ & Thickness & $41.351 \mathrm{~mm}$ \\
\hline Maximum tuning rate & $10 \mathrm{MHz} / \mathrm{s}$ & Fabry-Pérot FWHM & $51 \mathrm{pm} / 13.4 \mathrm{GHz}$ & Passband FWHM, $\Delta \lambda_{\mathrm{E}}$ & $100 \mathrm{MHz}$ \\
\hline Seed Laser & & Effective finesse & 26 & Off-axis beam angle & $1.22 \mathrm{mrad}$ \\
\hline $\begin{array}{l}\text { Mode-hop free tuning } \\
\text { range }\end{array}$ & $30.2 \mathrm{GHz}$ & Clear aperture & $60 \mathrm{~mm}$ & Receiver detector & \\
\hline Temperature sensitivity & $3 \mathrm{GHz} / \mathrm{K}$ & Input beam divergence & $0.6 \mathrm{mrad}$ full angle & Detector type & $\mathrm{HgCdTe}$ APD \\
\hline \multirow[t]{4}{*}{ Output power } & $15 \mathrm{~mW}$ & Maximum transmission & 0.9 & Quantum efficiency & $0.9 \mathrm{e}^{-} /$photon \\
\hline & & Diffractive optical element & & No. of pixels & $4 \times 4$ \\
\hline & & Substrate & Fused silica & $\begin{array}{l}\text { Temporal response } \\
\text { (FWHM) }\end{array}$ & $6 \mathrm{~ns}$ \\
\hline & & Separation angle & $1.2 \mathrm{mrad}$ & Noise-equivalent Power & $0.3 \mathrm{fW} / \mathrm{Hz}^{1 / 2}$ \\
\hline
\end{tabular}

(parallel-polarization) and that from the perpendicular polarization channel, yielding information on the vertical distribution of ice crystals [43].

The two beams from the fine etalon and the one from the cross-polarized channel are focused in three $113 \mu \mathrm{m}$ diameter spots on the HgCdTe APD surface. Each of the beams is focused onto separate $2 \times 2$ pixel quadrants of the detector. The HgCdTe APD has an APD gain of up to 900 and a 0.4 $\mathrm{fW} / \mathrm{Hz}^{1 / 2}$ noise equivalent power [58-61]. The detector chip and preamplifer are mounted within an integrated detector cooler assembly (IDCA) are shown in Fig. 7. A similar version of this IDCA was developed to TRL-6 under the NASA In-Space Validation of Earth Science Technologies (InVEST) program [62].

The MARLI receiver electronics sum the signals from the four pixels in each quadrant of the detector and digitize the signals from the three channels with an analog to digital converter (ADC). The ADC subsystem will measure the detector signal levels in $500 \mathrm{~ns}$ bins (corresponding to a 75-m vertical bins) for every laser pulse. Every $0.5 \mathrm{~s}$ the lidar will record the range-resolved measurements of the atmospheric backscatter in both parallel channels, and ratios of cross- to parallel-polarized backscatter will be recorded, along with instrument housekeeping data. After averaging those records, the LOS and horizontal wind profiles, the parallel polarized aerosol profile and the profile of the cross-polarized backscatter scatter will be computed. Although the amount of both the vertical and horizontal averaging are flexible, our performance analyses are based on using averaging of $2 \mathrm{~km}$ vertically and 2 degrees of latitude (40 s) horizontally.

\section{Doppler accuracy and bias control}

Accurate retrieval of the wind-induced Doppler shift depends on knowledge of the relative frequency offset of the transmitted laser pulses and the crossing-point of the double edge filter. Several factors can contribute to this offset including laser frequency stability, temperature changes of the double-edge filter, and the velocity of the surface with respect to the orbiting instrument. We discuss our monitoring and compensation approaches for these potential sources of bias below.

A seed laser is used to stabilize the center frequency of the ring oscillator of the laser transmitter. When first starting the laser, its frequency may be several gigahertz away from the double-edge filter's zero-crossing point. For broad frequency tuning, the seed laser's frequency can be tuned via temperature tuning of the seed laser crystal. To stabilize the laser frequency and/or offset a known bias, the seed laser frequency can be tuned at the $\mathrm{MHz}$ level via piezoelectric tuning the seed laser crystal.

We have developed a two-stage wavelength monitor subsystem that continuously samples the outgoing laser wavelength to monitor the seed laser's frequency as shown in Fig. 8. Our approach first directs a small portion $(<1 \%)$ 

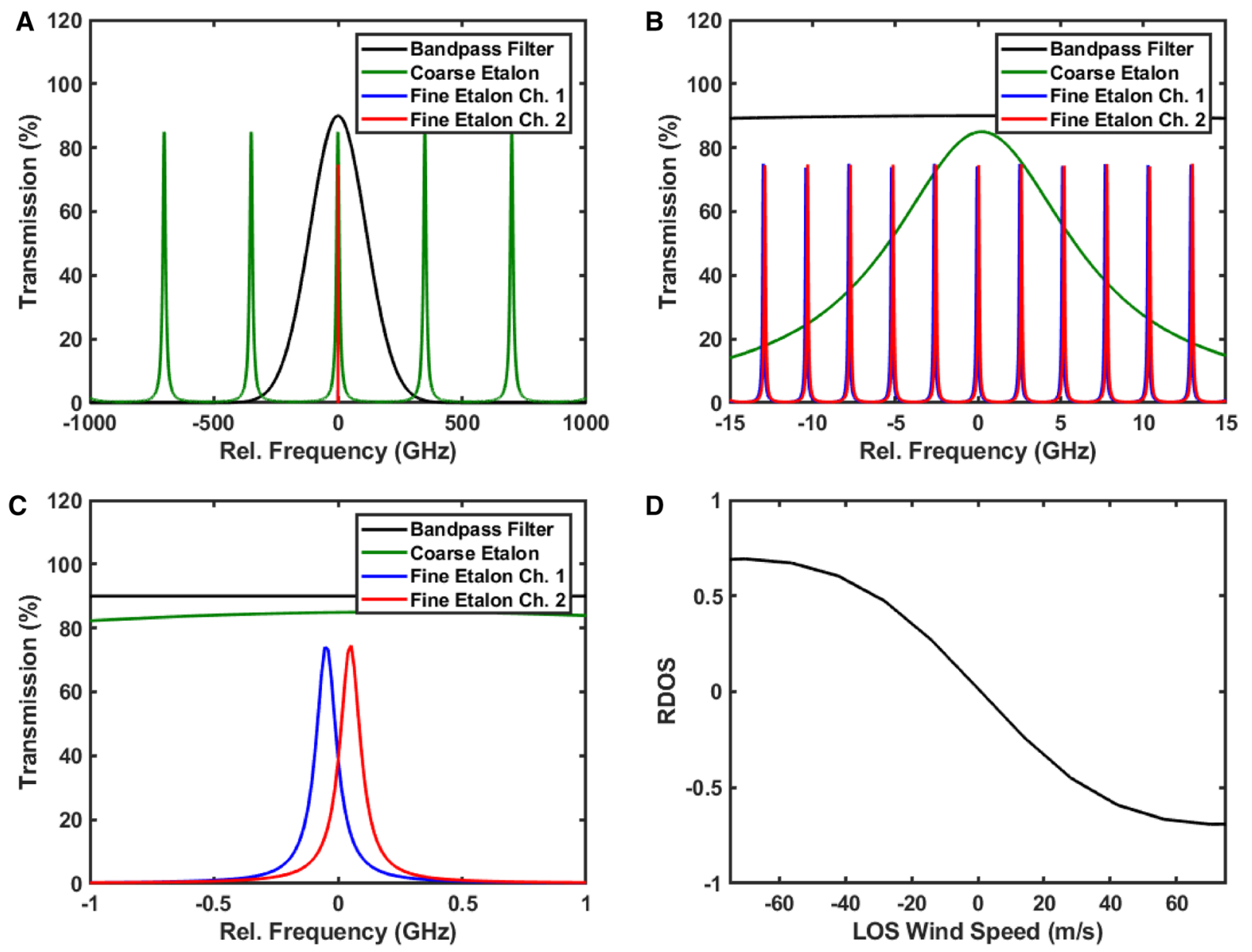

Fig. 6 Plots of the optical transmission versus frequency for the elements of the optical filter stack in the MARLI receiver. a The optical bandpass filter (black) rejects all but one transmission order of the air-gapped coarse etalon filter (green). Only one set of resonances for the fine etalon are shown in a for clarity. The relative frequency is defined as offset from the laser frequency. b An expanded region of a showing the transmissions curves of the coarse etalon and the two

channels of the fine etalon. $\mathbf{c}$ An expanded region of $\mathbf{b}$ showing the two transmission functions of the fine etalon, that together comprise the double edge filter. d The approximate Doppler retrieval curve computed from the ratio of the difference over the sum (RDOS) transmissions of the two edge filters for the relative frequency region from -70 to $+70 \mathrm{MHz}$

of the laser emission through a gapped Fabry-Pérot etalon which acts as an edge filter. This etalon is identical to the coarse etalon used in the receiver filter stack (Table 1) except that the incident angle is offset from normal by $6.71 \mathrm{mrad}$. This shifts the etalon's passband by $6.75 \mathrm{GHz}$, thus creating a single-edge filter. The signals from silicon photodiode detectors are used to temperature-tune the seed laser to the gapped etalon $50 \%$ transmission point, ensuring the laser is within the double-edge filter bandpass.

In the present design, a second, finer wavelength monitor stage utilizes the small area of the fine etalon in the receiver subsystem that is shadowed by the telescope secondary. We first direct a small portion of the transmitted laser energy via a single-mode optical fiber to the receiver subsystem. This monitor signal is directed from the optical fiber to a small mirror suspended via support vanes in front of the center

of the diffractive optical element. This creates two monitor beams that are offset in angle by $1.2 \mathrm{mrad}$. After the monitor beams pass through the etalon, a second small mirror reflects the two monitor beams out of the main receiver path and a focusing lens images them onto two elements of a silicon detector. The ratio of the signals on the two elements is used to tune and lock the seed laser frequency to the crossing point of the double edge filter. A similar wavelength tracking method was used successfully in the $532 \mathrm{~nm}$ receiver channel of the GLAS lidar on the ICESat mission [64].

The passbands of the double-edge filter are also temperature sensitive, so changes in its temperature can also introduce Doppler bias into the measurements. The temperature-dependence of the index of refraction of fused silica causes the passband frequency to shift by $355 \mathrm{MHz}$ for every $1{ }^{\circ} \mathrm{C}$ temperature change. For MARLI this leads to a 


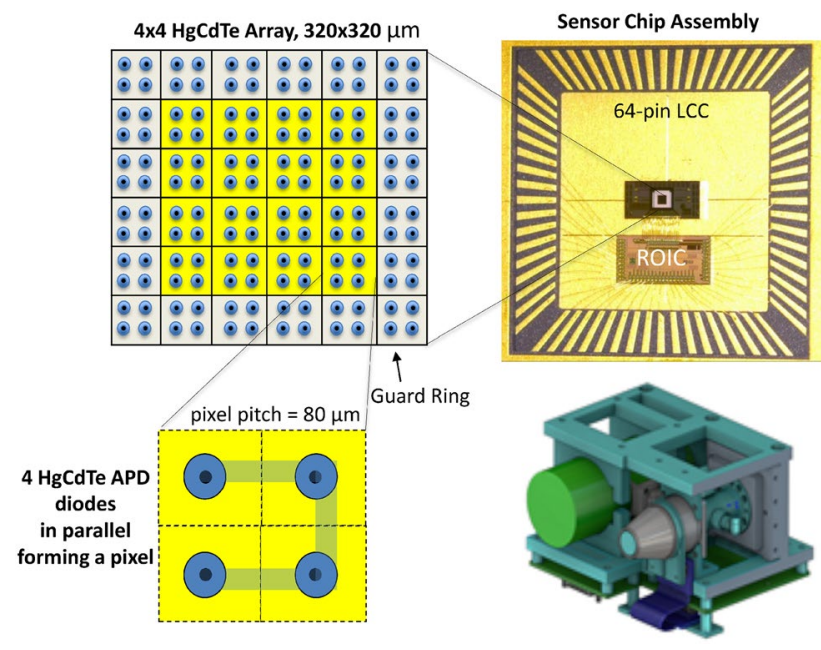

Fig. $7 \mathrm{HgCdTe}$ sensor chip assembly photograph and schematic adapted from [63]. (inset) A drawing of the integrated detector and cooler assembly (IDCA) being developed for the MARLI detector. The IDCA dimensions are approximately $10 \mathrm{~cm}$ by $20 \mathrm{~cm}$ by $10 \mathrm{~cm}$
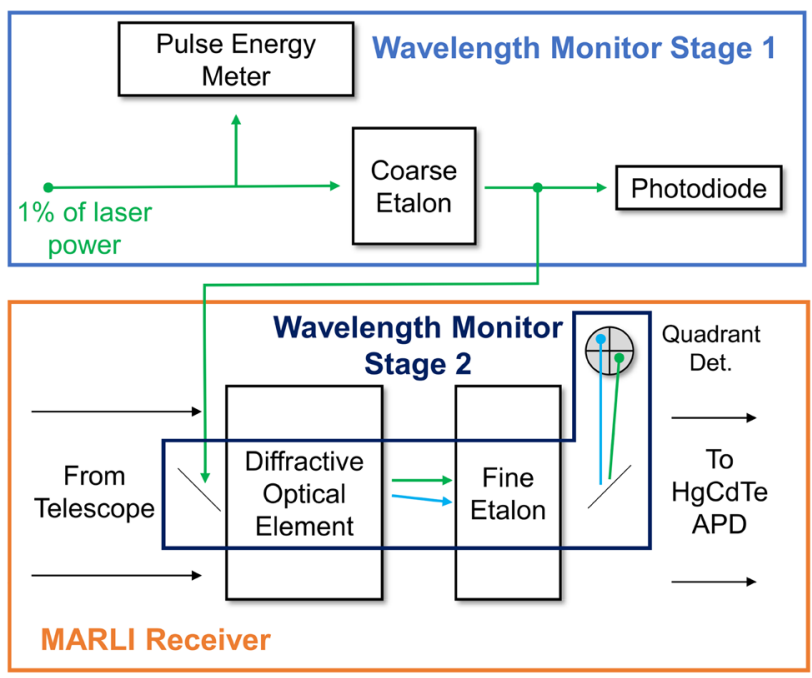

Fig. 8 Block diagram of the two-stage wavelength monitor subsystem. The second stage uses a small central portion of the DOE and fused silica etalon in the lidar receiver that are shadowed by the telescope's secondary mirror

requirement that the temperature of the fused silica etalon be held to $\pm 5 \mathrm{mK}$ for a passband stability of $1.77 \mathrm{MHz}$. In addition, the thermal gradients within the etalon must be minimized. Our present approach is to enclose the receiver's optical subsystem in a warm-biased insulated thermal enclosure (as in [45]), and to stabilize the enclosure's temperature.

In addition to instrument effects the rotation of Mars will induce a latitude-dependent sinusoidal Doppler signal caused by the cross-track pointing and polar orbit. Its amplitude is $\sim 213 \mathrm{MHz}$ and its period is $\sim 2 \mathrm{~h}$. The slow predictable nature and amplitude of this effect allows it to be compensated via piezoelectric tuning of the seed laser's frequency. The lidar return from the Mars surface may also be used as a reference for the transmitted laser frequency. The ratio of the surface return from the two Doppler channels can be used to monitor the relative offset of the laser frequency from the crossing point of the double-edge filter. This technique has the benefit of using the same optical path as the atmospheric backscatter signal.

\section{Instrument performance model}

We have developed a statistical model of the MARLI lidar measurements to guide instrument design and to predict the lidar's performance in orbit. Our approach builds on previous space lidar measurement models which we have developed while building and operating the Mars Orbiter Laser Altimeter (MOLA), the Geoscience Laser Altimeter System (GLAS) atmospheric lidar channel, the Mercury Laser Altimeter (MLA), and the Lunar Orbiter Laser Altimeter (LOLA). The model uses the demonstrated laser pulse energy and width, optical receiver parameters, and the detector response and noise characteristics. The instrument parameters are listed in Table 1, and detector characteristics can be found in recent publications $[59,65]$.

\subsection{Models of the mars atmosphere}

In order to estimate MARLI performance we selected several cases that represent the atmosphere under a range of atmospheric aerosol (dust and water ice) loading. Observations of the Mars atmosphere have revealed complex interactions between its dust, water and $\mathrm{CO}_{2}$ cycles $[5,8,66]$. The bulk of current spacecraft observations of the global Mars atmospheric state come from the Mars Global Surveyor (MGS) and Mars Reconnaissance Orbiter (MRO) spacecraft, which show large temporal variations in the amount and vertical distribution of dust and ice aerosols and water vapor [13, 17]. For this work we extracted aerosol profiles using extinction profiles (version 5.2.4) from the Mars Climate Sounder (MCS) on the MRO [67-69]. The MCS extinction retrievals were then scaled to the MARLI wavelength of $1064 \mathrm{~nm}$ [70]. We chose to neglect molecular scattering since it is so small at the low atmospheric pressure of Mars [9].

The first atmospheric case was chosen to represent a relatively dust-free atmosphere, where water ice scattering would make up a significant portion of the backscattered signal. This was drawn from MCS data averaged over Northern Hemisphere spring $\left(L_{\mathrm{s}}=5^{\circ}-30^{\circ}\right)$ of Mars year 34 (MY34) northern latitudes $\left(60^{\circ} \mathrm{N}-80^{\circ} \mathrm{N}\right)$. The second case was an average from Southern Hemisphere spring $\left(L_{\mathrm{s}}=150^{\circ}-230^{\circ}\right)$ of MY33 mid-latitudes $\left(50^{\circ} \mathrm{S}-25^{\circ} \mathrm{N}\right)$, representing an 
intermediate dust scattering case. Finally, a model was created from MCS data during the MY34 global dust storm $\left(80^{\circ} \mathrm{S}-80^{\circ} \mathrm{N}\right)$ to calculate lidar performance under high dust loading. The extinction profiles were linearly extrapolated to the surface as a function of height in cases where full-height data from MCS retrievals were not available.

For these models the extinction to backscatter ratio for dust was assumed to be 40 steradians based on measurements made by the lidar on the Mars Phoenix lander mission [71]. This ratio is also consistent with values for desert aerosols on Earth [72]. For water ice the extinction to backscatter ratio was assumed to be 15 steradians based on measurements from the Mars Phoenix lidar [73]. The cirruslike nature of clouds on Mars [42] led us to assume an ice depolarization ratio $\left(\beta_{\perp} / \beta_{\|}\right)$of 0.47 , taken from $1064 \mathrm{~nm}$ elastic lidar measurements of cirrus clouds [74] that formed above Earth. The parallel-polarized backscatter signal is thus a combination of scattering from dust and ice, while the perpendicularly-polarized backscatter was assumed to be from ice. The backscatter profiles used to determine the instrument performance are the attenuated parallel (Fig. 9a) and perpendicular (Fig. 9b) profiles for each of the three atmospheric cases.

\subsection{Double-edge Fabry-Perot Etalon}

The optical transmission wavelength [75] of the receiver's fine etalon is given by

$\eta_{\mathrm{E}}(\lambda)=\frac{\eta_{\mathrm{pk}}}{1+\left(\frac{2 \mathcal{F}}{\pi}\right)^{2} \sin ^{2}\left[\frac{1}{2} \delta\left(\lambda, \theta, F_{\lambda}\right)\right]}$

where $\eta_{\mathrm{pk}}$ is the peak transmission, $\mathcal{F}$ is the finesse of the etalon, $F_{\lambda}$ is the free spectral range, $\delta\left(\lambda, \theta, F_{\lambda}\right)$ is the phase delay of the light after each pass through the etalon, $\lambda$ is the optical wavelength, and $\theta$ is the light incident angle. The phase difference in Eq. (1) is given by

$\delta\left(\lambda, \theta, F_{\lambda}\right)=\frac{2 \pi}{\lambda} \cdot \frac{\lambda_{c}^{2}}{F_{\lambda}} \cos \left(\frac{\theta}{n_{\mathrm{E}}}\right)$

with $\lambda_{\mathrm{c}}$ the wavelength at the peak transmission and $n_{\mathrm{E}}$ is the etalon index of refraction. For a fused silica etalon $n_{\mathrm{E}}=1.45$. The center wavelength is rounded to the nearest integer value for mathematical convenience. In practice, the etalon wavelength is temperature-tuned to within the operating range of the laser.

The fine etalon design for MARLI has a peak transmission of $70 \%$, a free spectral range of $2.5 \mathrm{GHz}$ and a pass band of $0.1 \mathrm{GHz}$. The rest of the etalon parameters can be derived [75] and are listed in Table 1. For illumination at small offsets from normal incidence, the etalon transmission
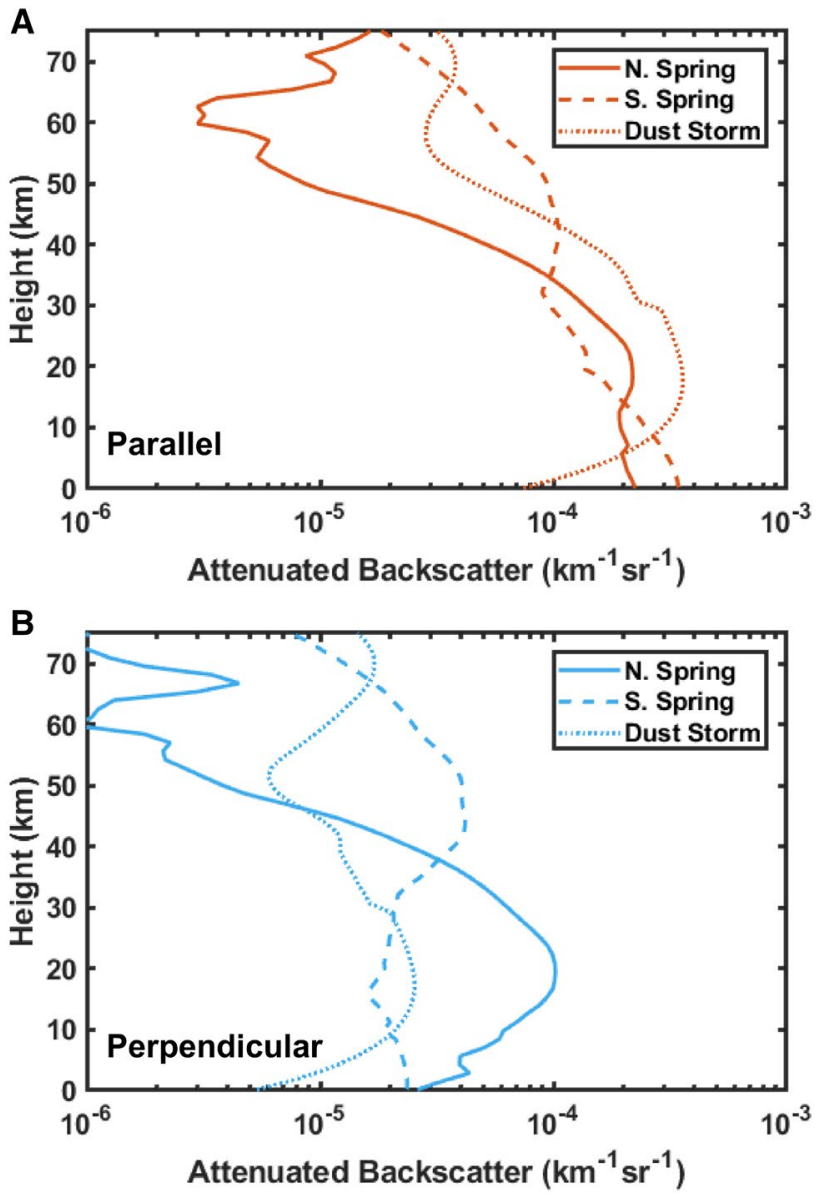

Fig. 9 The Mars atmospheric backscatter profiles used to predict MARLI measurement performance were computed from MCS retrievals. a Attenuated backscatter $\left(\beta T^{2}\right)$ with polarization parallel to the transmitter for the three atmospheric test cases as a function of altitude. b Attenuated backscatter with polarization perpendicular to the transmitter for the same three cases

is similar to that at normal incidence, but the peak transmission is shifted slightly longer in wavelength and the peak becomes asymmetrical, broadening on the higher frequency edge $[55,76]$. We note that an accurate calculation of the full etalon response for this beam would include effects of a three-dimensional beam with finite divergence [77]. Our simplifying approximation of using two symmetrical filter edges was made because in the DEFP method the received signal only passes through the low-frequency edge of the off-axis bandpass. In practice we can also measure the etalon transmission versus frequency for both beams once the etalon is mounted in the receiver subsystem to determine the actual double-edge response function.

For the double-edge wind measurement, the MARLI approach calculates the ratio of the difference to the sum (RDOS) of the signals through the etalon as 


$$
f_{\mathrm{DE}}(\lambda)=\frac{\eta_{\mathrm{E} 0}(\lambda)-\eta_{\mathrm{E} 1}(\lambda)}{\eta_{\mathrm{E} 0}(\lambda)+\eta_{\mathrm{E} 1}(\lambda)}
$$

where $f_{\mathrm{DE}}(\lambda)$ is the double-edge etalon response function, and $\eta_{\mathrm{E} 0}(\lambda)$ and $\eta_{\mathrm{E} 1}(\lambda)$ are the etalon transmission at the normal and slightly off-axis incidence angles, and $\lambda$ is the Doppler-shifted wavelength. The off-axis angle is chosen such that the low-frequency edge of the off-axis etalon transmission curve crosses the on-axis etalon transmission curve at the midpoint, as shown in Fig. 6. The Doppler shift in the backscattered signal is related to the wind speed $v_{\mathrm{w}}$ by

$\Delta \lambda_{\mathrm{D}}=2 \lambda_{0} v_{\mathrm{w}} / c$

where $c$ the speed of light and $\lambda_{0}$ is the transmitted laser wavelength. The Doppler profile in the LOS direction can be expressed as

$v_{\mathrm{w}}(h)=\frac{1}{2 \lambda_{0}} f_{\mathrm{DE}}^{-1}\left(\frac{N_{\mathrm{s} 0}(h)-N_{\mathrm{s} 1}(h)}{N_{\mathrm{s} 0}(h)+N_{\mathrm{s} 1}(h)}\right)$

Here $f_{\mathrm{DE}}^{-1}(\cdot)$ is the inverse function of Eq. (3), which can be obtained numerically, and $N_{\mathrm{s} 0}(h)$ and $N_{\mathrm{s} 1}(h)$ are the net received signal through the etalon in the on-axis and offaxis channels integrated over a given atmosphere layer and a number of repeated measurements. Figure 10 shows a plot of the RDOS of the etalon transmission as a function of the cross-track horizontal wind speed. The derivative of the RODS with respect to the wind speed is also plotted. We designate this derivative as the Error Multiplier, which is the factor by which the sensitivity of the double edge filter is reduced as the Doppler shift increases in amplitude. The plot shows the present MARLI etalon design allows estimating horizontal wind speeds to $\pm 60 \mathrm{~m} / \mathrm{s}$ in the viewing direction

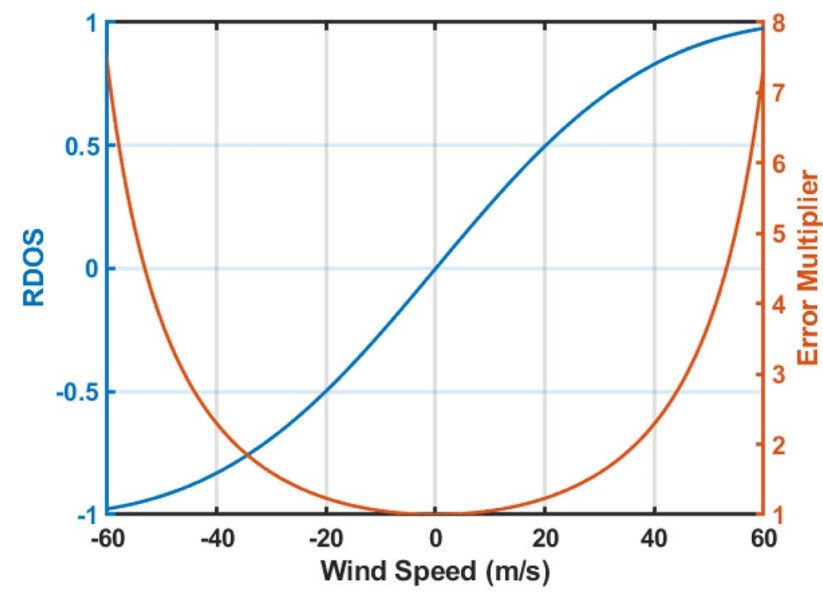

Fig. 10 Response of the receiver ratio of the difference over the sum of the double edge etalon filter (in blue) and the measurement error multiplier (in red) versus the cross-track horizontal wind speed. These plots are for the present etalon used in the lidar prototype and that wind speeds of $\pm 45 \mathrm{~m} / \mathrm{s}$ can be measured with an Error Multiplier $<3$.

\subsection{Expected wind measurement uncertainty}

The lidar receiver signal passing through the double-edge filter in the on-axis direction can be written as [78],

$$
\begin{aligned}
N_{\mathrm{s} 0}(h) & =\frac{1}{h f} T_{\mathrm{av}} \int_{h-\Delta H / 2}^{h+\Delta H / 2} E_{\mathrm{t}}\left[\beta(h) T^{2}(h)\right] \eta_{\mathrm{a}}^{2} \\
& \frac{\eta_{\mathrm{O}} A_{\mathrm{T}}}{\left[\left(H_{\mathrm{s}}-h\right) / \cos \theta_{\mathrm{p}}\right]^{2}} \eta_{\mathrm{E}}\left(\Delta \lambda_{\mathrm{D}}\right) \frac{c}{2} d h
\end{aligned}
$$

where $N_{\mathrm{s} 0}(h)$ is the total number of the integrated signal photons from the on-axis path from the atmosphere layer at altitude $h$ of thickness $\Delta H(2 \mathrm{~km})$ and from averaging time, $T_{\mathrm{av}}$, of $40 \mathrm{~s}, h f$ is the photon energy, $E_{\mathrm{t}}$ is the laser pulse energy, $\beta(h)$ is the atmosphere volume backscatter coefficient per polarization axis in $1 / \mathrm{m}$-sr at altitude $h, T^{2}(h)$ is the two-way optical transmission of the atmosphere layer being measured, $\eta_{\mathrm{a}}^{2}$ is the two-way transmission from the upper atmosphere not included in $T^{2}(h), \eta_{\mathrm{O}}$ is the optical transmission of the MARLI receiver optics including the bandpass filter, polarization beamsplitters, and coarse etalon, $A_{\mathrm{T}}$ is the receiver telescope aperture area, $H_{\mathrm{s}}$ is the spacecraft orbit altitude, $\theta_{\mathrm{p}}$ is the laser beam pointing angle from nadir direction, and $\eta_{\mathrm{E}}\left(\Delta \lambda_{\mathrm{D}}\right)$ is the on-axis etalon transmission with Doppler shift $\Delta \lambda_{\mathrm{D}}$ due to the LOS wind. The signal passing through the etalon at the off-axis angle can be calculated by replacing $\eta_{\mathrm{E} 0}\left(\Delta \lambda_{\mathrm{D}}\right)$ with $\eta_{\mathrm{E} 1}\left(\Delta \lambda_{\mathrm{D}}\right)$ in Eq. (6).

The average background photons per range bin detected by the receiver can be calculated from

$$
\left\langle N_{\mathrm{bg}}\right\rangle=\frac{1}{2} \cdot \frac{1}{h f} T_{\mathrm{av}} I_{\lambda} \frac{\rho}{\pi} \Delta \lambda_{\mathrm{f}} \eta_{\mathrm{a}}^{2} \eta_{\mathrm{O}} A_{\mathrm{T}} \pi\left(\frac{\theta_{\mathrm{FOV}}}{2}\right)^{2} \eta_{\mathrm{pk}} \Delta H \frac{2}{c}
$$

where $I_{\lambda}$ is the spectral irradiance from the Sun $(277 \mathrm{~W} / \mathrm{m} \mu \mathrm{m})$ at $1064 \mathrm{~nm}, \rho$ is the assumed surface reflectance $(0.26), \Delta \lambda_{\mathrm{f}}$ is the equivalent filter bandwidth calculated from integrating the filter stack transmission over the passband, and $\theta_{\mathrm{FOV}}$ is the receiver field of view. The factor of $1 / 2$ in Eq. (7) accounts for the effect of the polarization beamsplitter which reflects $1 / 2$ the solar background light. There is also detector dark noise $N_{\mathrm{D}}$ which is $55 \mathrm{kHz}$ for each pixel, with four pixels being summed per channel for a dark noise rate of $220 \mathrm{kHz}$. The integration time for the SNR computations is $40 \mathrm{~s}(10,000$ shots $)$ and measurements are made in 2-km range bins $(\Delta H)$.

For the HgCdTe APD detector used in MARLI, the performance is nearly shot-noise limited [59] and hence the variance of the detected signal can be approximated by the 
sum of the mean signal, solar background, and the detector dark counts. The variance of the RDOS terms from the double-edge etalon can be approximated by first taking the partial derivatives of Eq. (3) with respective to each signal and then computing the variance assuming the two output signals from the double edge etalon are independent, as, the lowest 3 scale heights. The MARLI performance models show its wind speed retrievals typically show random errors $<4 \mathrm{~m} / \mathrm{s}$ in the lowest $\sim 3$ scale heights under the three dust-loading conditions considered. Since the vast majority of atmospheric transport of dust, water, and trace species occurs in this region of the atmosphere MARLI's precision

$\operatorname{VAR}\left\{\frac{N_{\mathrm{s} 0}(h)-N_{\mathrm{s} 1}(h)}{N_{\mathrm{s} 0}(h)+N_{\mathrm{s} 1}(h)}\right\} \approx \operatorname{VAR}\left\{\frac{\partial\left[\frac{N_{\mathrm{s} 0}(h)-N_{\mathrm{s} 1}(h)}{N_{\mathrm{s} 0}(h)+N_{\mathrm{s} 1}(h)}\right]}{\partial N_{\mathrm{s} 0}(h)} \delta N_{\mathrm{s} 0}(h)+\frac{\partial\left[\frac{N_{\mathrm{s} 0}(h)-N_{\mathrm{s} 1}(h)}{N_{\mathrm{s} 0}(h)+N_{\mathrm{s} 1}(h)}\right]}{\partial N_{\mathrm{s} 1}(h)} \delta N_{\mathrm{s} 1}(h)\right\}$

Here $\delta N_{\mathrm{s} 0}(h)$ denotes the random noise from the on-axis etalon output, and $\operatorname{VAR}\left\{\delta N_{\mathrm{s} 0}(h)\right\} \approx N_{\mathrm{s} 0}(h)+2 N_{\mathrm{bg}}+2 N_{\mathrm{D}}$. The noise terms from the background photons and dark counts are multiplied by two because the approach separately estimates the background between the laser pulses and subtracts it from the total when the laser pulse is present. The random error in the wind velocity measurement can be approximated by multiplying results from Eq. (8) by the error multiplier given in Fig. 10.

To determine a nominal wind speed with which to calculate instrument performance, we calculated the mass (i.e. pressure) weighted wind speed on Mars (combining the zonal and meridional winds) over the entire year over the globe. The result was an average speed of $18 \mathrm{~m} / \mathrm{s}$. The results of the instrument model are shown in Fig. 11 for a crosstrack, horizontal nominal wind speed of $18 \mathrm{~m} / \mathrm{s}$. The results of the instrument model suggest the instrument is particularly sensitive to wind in the lower atmosphere, with random error between 1.5 and $6 \mathrm{~m} / \mathrm{s}$ (for dust storms) at the surface.

The scale height of the Mars atmosphere is $\sim 11.1 \mathrm{~km}$, and approximately $95 \%$ of the atmospheric mass is contained in

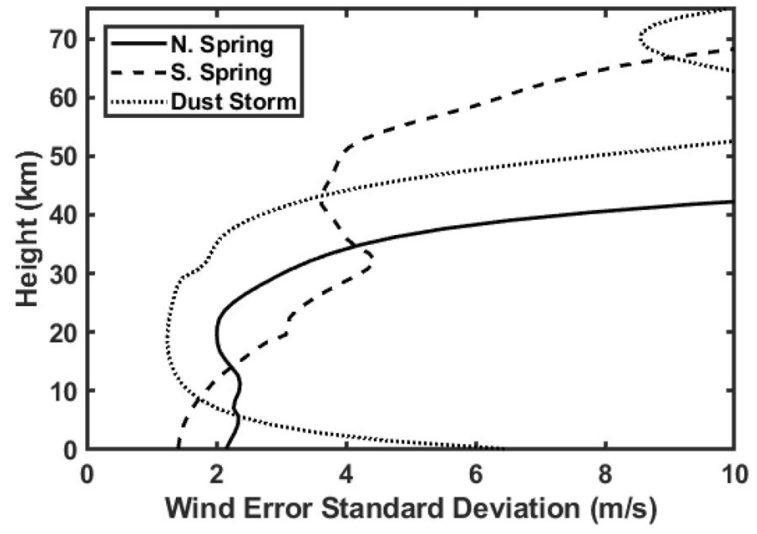

Fig. 11 The RMS wind-speed uncertainty from the MARLI instrument model computed as a function of altitude from the surface for the case of a uniform cross-track horizontal wind speed of $18 \mathrm{~m} / \mathrm{s}$. This uncertainty will be modified at different wind speeds via the error multiplier shown in Fig. 8 enables discrimination of the transport characteristics of the mean atmospheric circulation (i.e., the Hadley circulation) and intermittent/irregular processes such as baroclinic and barotropic waves, atmospheric tides, and stationary waves. Understanding Mars atmospheric transport is key for resolving long standing questions about the Mars atmosphere and climate. This precision is also sufficient for evaluating general circulation models and for assimilating MARLI measurements into improved atmospheric models.

\subsection{Relative error of atmospheric backscatter profile measurements}

The characteristics of the backscatter profile measurement were calculated in a similar manner, but by summing the signals from the normal incidence and off-axis signals from Eq. (6). Figure 12a shows the relative error, defined as the ratio of the standard deviation to the mean for the atmosphere backscatter profile measurements in the parallel polarization. The relative error for the cross-polarization (perpendicular) channel was obtained similarly by using the passband width for the coarse filter only and the optical transmission without the etalon and the beam splitting optics. The uncertainty in depolarization ratio can be calculated from the relative errors of the parallel and perpendicular polarization channels.

MARLI's sensitivity to dust and water ice aerosols is particularly advantageous in the atmospheric boundary layer and lowest pressure scale height in the atmosphere, where existing observations (e.g., from MCS and the Thermal Emission Spectrometer) are either insensitive (due to high line-of-sight opacity in limb-viewing geometry) or have only coarse resolution. This unique ability to resolve the near-surface region of atmosphere at $2 \mathrm{~km}$ vertical resolution will help resolve questions regarding dust lifting processes, sources and sinks of dust, and how dust is transported through the atmosphere. Additionally, MARLI's $2 \mathrm{~km}$ vertical resolution is superior to existing dust observation climatologies and will help better resolve mesoscale phenomena such as high-altitude dust layers and dust plumes. 

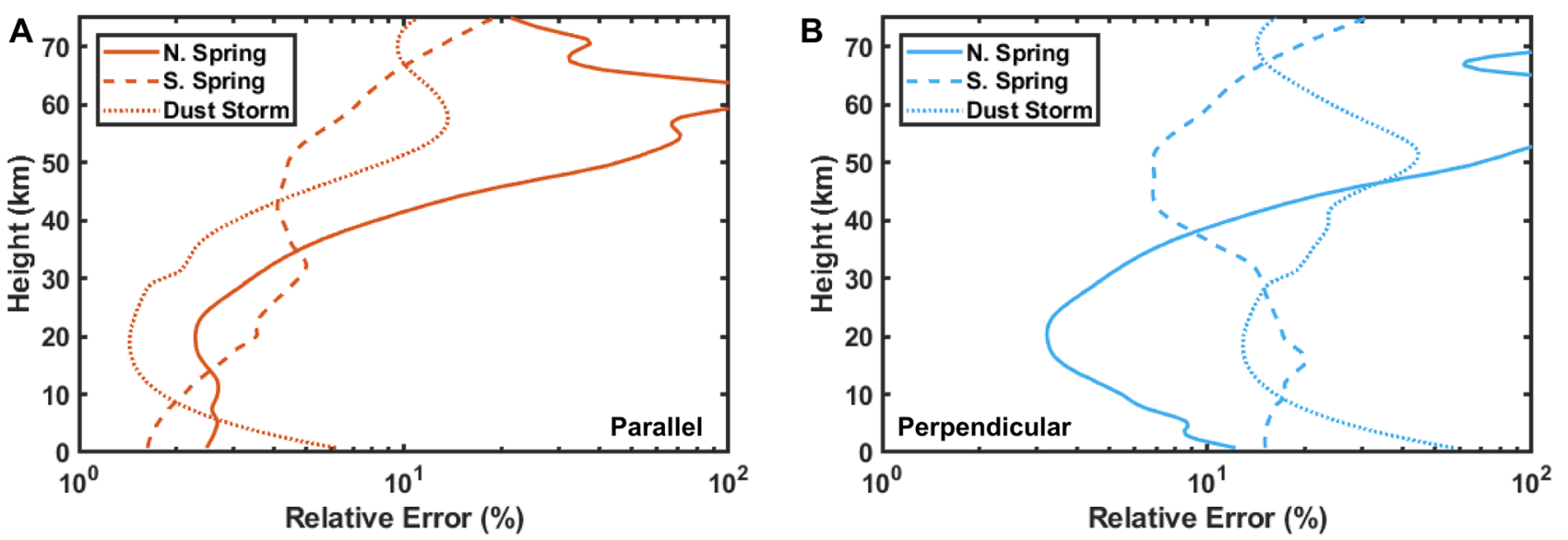

Fig. 12 Expected relative error as a function of height of the MARLI atmospheric backscatter profile measurements in the parallel (a) and cross polarization (b) channels. Due to their wide variation, the relative errors are plotted on a log scale

\section{Future work}

We are currently building a prototype instrument using a prototype laser transmitter and the optical receiver described above with a $14-\mathrm{cm}$ diameter receiver telescope, and the integrated detector-cooler assembly. Our plans are to demonstrate wind measurements using lidar backscatter from thin cirrus clouds in Earth's atmosphere, which approximate the backscatter characteristics of the Mars atmosphere. We are also testing the thermal design of the double-edge filter assembly to verify its performance in air and in vacuum. In addition, we will continue to develop our instrument model to include factors such as laser frequency stability and etalon thermal stability. We will also perform a trade study to optimize the passband width of the double-edge filter based on the expected dynamic range of winds in the Mars atmosphere. The objective is to find the best tradeoff between using a broader linewidth etalon to expand the wind measurement dynamic range versus the impact of increasing the wind measurement uncertainty at lower wind speeds.

\section{Summary}

We are developing MARLI, a direct detection wind and aerosol lidar for Mars orbit. The design uses a pulsed singlefrequency Nd:YAG laser and the double-edge Fabry-Pérot technique to resolve the Doppler shift in the atmospheric backscatter profiles. MARLI is being designed to provide global, height-resolved measurements of LOS winds, aerosol backscatter, and depolarization ratio. We have developed an instrument performance model that includes measured atmospheric scattering for a range of Mars atmospheric conditions. The performance has been calculated assuming averaging of $40 \mathrm{~s}\left(2^{\circ}\right.$ in latitude) with a vertical resolution of
$2 \mathrm{~km}$. The results show typically $<4 \mathrm{~m} / \mathrm{s}$ random error wind measurements from the surface to $35 \mathrm{~km}$. We have developed breadboards and prototypes of the laser, wavelength locking method, the receiver optics, and detector. Ongoing work involves completing the prototypes and demonstrating measurements to thin cirrus clouds in Earth's atmosphere.

Acknowledgements We thank the reviewers and editor for their many helpful comments on the manuscript. Funding provided by NASA ROSES NNH13ZDA001N-PICASSO (2013) and NASA ROSES NNH16ZDA001N-MATISSE (2016). Dr. Cremons' research was supported by an appointment to the NASA Postdoctoral Program at the NASA Goddard Space Flight Center, administered by Universities Space Research Association under contract with NASA.

Open Access This article is licensed under a Creative Commons Attribution 4.0 International License, which permits use, sharing, adaptation, distribution and reproduction in any medium or format, as long as you give appropriate credit to the original author(s) and the source, provide a link to the Creative Commons licence, and indicate if changes were made. The images or other third party material in this article are included in the article's Creative Commons licence, unless indicated otherwise in a credit line to the material. If material is not included in the article's Creative Commons licence and your intended use is not permitted by statutory regulation or exceeds the permitted use, you will need to obtain permission directly from the copyright holder. To view a copy of this licence, visit http://creativecommons.org/licenses/by/4.0/.

\section{References}

1. Holstein-Rathlou, C., Gunnlaugsson, H.P., Merrison, J.P., Bean, K.M., Cantor, B.A., Davis, J.A., Davy, R., Drake, N.B., Ellehoj, M.D., Goetz, W., Hviid, S.F., Lange, C.F., Larsen, S.E., Lemmon, M.T., Madsen, M.B., Malin, M., Moores, J.E., Nørnberg, P., Smith, P., Tamppari, L.K., Taylor, P.A.: Winds at the phoenix landing site. J. Geophys. Res. Planets 115, E00E18 (2010). https ://doi.org/10.1029/2009je003411

2. Desai, P.N., Prince, J.L., Queen, E.M., Schoenenberger, M.M., Cruz, J.R., Grover, M.R.: Entry, descent, and landing performance 
of the mars phoenix Lander. J. Spacecr. Rockets. 48, 798-808 (2011). https://doi.org/10.2514/1.48239

3. Madeleine, J.B., Forget, F., Millour, E., Montabone, L., Wolff, M.J.: Revisiting the radiative impact of dust on Mars using the LMD global climate model. J. Geophys. Res. Planets 116, E11010 (2011). https://doi.org/10.1029/2011je003855

4. McCleese, D.J., Heavens, N.G., Schofield, J.T., Abdou, W.A., Bandfield, J.L., Calcutt, S.B., Irwin, P.G.J., Kass, D.M., Kleinböhl, A., Lewis, S.R., Paige, D.A., Read, P.L., Richardson, M.I., Shirley, J.H., Taylor, F.W., Teanby, N., Zurek, R.W.: Structure and dynamics of the Martian lower and middle atmosphere as observed by the Mars Climate Sounder: seasonal variations in zonal mean temperature, dust, and water ice aerosols. J. Geophys. Res. 115, E12016 (2010). https://doi.org/10.1029/2010JE003677

5. Smith, M.D.: Spacecraft observations of the Martian atmosphere. Annu. Rev. Earth Planet. Sci. 36, 191-219 (2008). https ://doi.org/10.1146/annurev.earth.36.031207.124334

6. Lee, C., Richardson, M.I., Mischna, M.A., Newman, C.E.: Realistic dust and water cycles in the MarsWRF GCM using coupled two-moment microphysics. In: American Astronomical Society, DPS Meeting \#49 (2017)

7. Segura, T.L., Toon, O.B., Colaprete, A.: Modeling the environmental effects of moderate-sized impacts on Mars. J. Geophys. Res. Planets 113, E1 1007 (2008). https://doi.org/10.1029/2008j e003147

8. Smith, M.D.: Interannual variability in TES atmospheric observations of Mars during 1999-2003. Icarus 167, 148-165 (2004)

9. Read, P.L., Lewis, S.R., Mulholland, D.P.: The physics of Martian weather and climate: a review. Rep. Prog. Phys. 78, 125901 (2015). https://doi.org/10.1088/0034-4885/78/12/125901

10. Gierasch, P.J., Goody, R.M.: The effect of dust on the temperature of the Martian atmosphere. J. Atmos. Sci. 29, 400-402 (1972). https://doi.org/10.1175/1520-0469(1972)029\%3c040 0 :TEODOT\%3e2.0.CO;2

11. McEwen, A.S., Dundas, C.M., Mattson, S.S., Toigo, A.D., Ojha, L., Wray, J.J., Chojnacki, M., Byrne, S., Murchie, S.L., Thomas, N.: Recurring slope lineae in equatorial regions of Mars. Nat. Geosci. 7, 53-58 (2014). https://doi.org/10.1038/ngeo2014

12. Ojha, L., Wilhelm, M., Murchie, S., McEwen, A.S., Wray, J.J., Hanely, J., Masse, M., Chojnacki, M.: Spectral evidence for hydrated salts in recurring slope lineae on Mars. Nat. Geosci. 8, 829-932 (2015)

13. Heavens, N.G., Richardson, M.I., Kleinbhöl, A., Kass, D.M., McCleese, D.J., Abdou, W., Benson, J.L., Schofield, J.T., Shirley, J.H., Wolkenberg, P.M.: Vertical distribution of dust in the Martian atmosphere during northern spring and summer: Observations by the Mars Climate Sounder and analysis of zonal average vertical dust profiles. J. Geophys. Res. Planets 116, 2011 (2011). https://doi.org/10.1029/2010je003691

14. Guzewich, S.D., Talaat, E.R., Toigo, A.D., Waugh, D.W., McConnochie, T.H.: High-altitude dust layers on Mars: observations with the thermal emission spectrometer. J. Geophys. Res. Planets 118, 1177-1194 (2013). https://doi.org/10.1002/jgre.20076

15. Montmessin, F., Quémerais, E., Bertaux, J.L., Korablev, O., Rannou, P., Lebonnois, S.: Stellar occultations at UV wavelengths by the SPICAM instrument: retrieval and analysis of Martian haze profiles. J. Geophys. Res. Planets. (2006). https:// doi.org/10.1029/2005JE002662

16. Cantor, B.A.: MOC observations of the 2001 Mars planetencircling dust storm. Icarus 186, 60-96 (2007). https://doi. org/10.1016/j.icarus.2006.08.019

17. McConnochie, T.M., Smith, M.D.: Vertically resolved aerosol climatology from Mars Global Surveyor Thermal Emission Spectrometer (MGS-TES) limb sounding. In: Third international workshop on the mars atmosphere: modeling and observations (2008)
18. Kleinböhl, A., Schofield, J.T., Kass, D.M., Abdou, W.A., Backus, C.R., Sen, B., Shirley, J.H., Lawson, W.G., Richardson, M.I., Taylor, F.W., Teanby, N.A., McCleese, D.J.: Mars climate sounder limb profile retrieval of atmospheric temperature, pressure, and dust and water ice opacity. J. Geophys. Res. Planets 2009, 114 (2009). https://doi.org/10.1029/2009je003358

19. Smith, M.D., Wolff, M.J., Clancy, R.T., Kleinböhl, A., Murchie, S.L.: Vertical distribution of dust and water ice aerosols from CRISM limb-geometry observations. J. Geophys. Res. Planets 118, 321-334 (2013). https://doi.org/10.1002/jgre.20047

20. Heavens, N.G., Benson, J.L., Kass, D.M., Kleinböhl, A., Abdou, W.A., McCleese, D.J., Richardson, M.I., Schofield, J.T., Shirley, J.H., Wolkenberg, P.M.: Water ice clouds over the Martian tropics during northern summer. Geophys. Res. Lett. 37, L18202 (2010). https://doi.org/10.1029/2010GL044610

21. MEPAG.: Mars Scientific Goals, Objectives, Investigations, and Priorities: 2015. In: Hamilton, V. (ed.), 74 p. white paper posted June, 2015 by the Mars Exploration Program Analysis Group (MEPAG) at http://mepag.nasa.gov/reports.cfm

22. Smith, M.D., Conrath, B.J., Pearl, J.C., Christensen, P.R.: Thermal emission spectrometer observations of Martian planet-encircling dust storm 2001A. Icarus 157, 259-263 (2002). https://doi. org/10.1006/icar.2001.6797

23. Toigo, A.D., Richardson, M.I., Wang, H., Guzewich, S.D., Newman, C.E.: The cascade from local to global dust storms on Mars: temporal and spatial thresholds on thermal and dynamical feedback. Icarus 302, 514-536 (2018). https://doi.org/10.1016/j.icaru s.2017.11.032

24. Voosen, P.: Windy season fails to revive fading Mars rover. Science 363, 439 (2019)

25. Murphy, J.R., Leovy, C.B., Tillman, J.E.: Observations of Martian surface winds at the Viking Lander 1 Site. J. Geophys. Res. (1990). https://doi.org/10.1029/JB095iB09p14555

26. Pla-Garcia, J., Rafkin, S.C.R., Kahre, M., Gomez-Elvira, J., Hamilton, V.E., Navarro, S., Torres, J., Marín, M.R., Vasavada, A.: The meteorology of Gale crater as determined from rover environmental monitoring station observations and numerical modeling. Part I: comparison of model simulations with observations. Icarus. 280, 103-113 (2016). https://doi.org/10.1016/j.icarus.2016.03.013

27. Holton, J.R., Hakim, G.J: An introduction to dynamic meteorology. Academic Press (1979)

28. Chevrier, V.F., Rivera-Valentin, E.G.: Formation of recurring slope lineae by liquid brines on present-day Mars. Geophys. Res. Lett. 39, L21202 (2012). https://doi.org/10.1029/2012GL054119

29. Orosei, R., Lauro, S.E., Pettinelli, E., Cicchetti, A., Coradini, M., Cosciotti, B., Di Paolo, F., Flamini, E., Mattei, E., Pajola, M., Soldovieri, F., Cartacci, M., Cassenti, F., Frigeri, A., Giuppi, S., Martufi, R., Masdea, A., Mitri, G., Nenna, C., Noschese, R., Restano, M., Seu, R.: Radar evidence of subglacial liquid water on Mars. Science 361, 490-493 (2018)

30. Kok, J.F.: Difference in the wind speeds required for initiation versus continuation of sand transport on mars: Implications for dunes and dust storms. Phys. Rev. Lett. (2010). https://doi.org/10.1103/ PhysRevLett.104.074502

31. Parteli, E.J.R., Herrmann, H.J.: Saltation transport on mars. Phys. Rev. Lett. 98, 198001 (2007). https://doi.org/10.1103/PhysRevLet t.98.198001

32. Greeley, R., Skypeck, A., Pollack, J.B.: Martian aeolian features and deposits: comparisons with general circulation model results. J. Geophys. Res. Planets. 98, 3183-3196 (1993). https://doi. org/10.1029/92je02580

33. Space Studies Board: National research council: vision and voyages for planetary science in the decade 2013-2022. National Academies Press, Washington, DC (2011) 
34. Abshire, J., Smith, M., Riris, H., Sun, X., Gentry, B.M., Yu, A., Allan, G.R.: MARLI: MARs LIdar for global wind profiles from orbit. In: European Planetary Science Congress 2015 (2015)

35. Guzewich, S., Abshire, J., Smith, M.D., Riris, H., Sun, X., Gentry, B.M., Yu, A., Allan, G.R.: MARLI: MARs LIdar for global wind profiles from orbit. In: 47th Lunar and Planetary Science Conference, p. 1497 (2016)

36. Abshire, J., Guzewich, S., Smith, M., Riris, H., Sun, X., Gentry, B.M., Yu, A., Allan: MARLI: MARs LIdar for global wind profiles and aerosol profiles from orbit. In: 3rd International Workshop on Instrumentation for Planetary Missions (2016)

37. Abshire, J., Guzewich, S., Smith, M., Riris, H., Allan, G.R.: Observations of Planetary Atmospheric Winds and Gases with Lidar. In: Planetary Science Vision 2050 Workshop, p. 8102 (2017)

38. Cremons, D.R., Abshire, J.B., Smith, M.D., Guzewich, S.D., Riris, H., Sun, X., Yu, A.W., Allan, G., Hovis, F.: Development of a Mars lidar (MARLI) for measuring wind and aerosol profiles from orbit. In: Lidar Technologies, Techniques, and Measurements for Atmospheric Remote Sensing XIV, p. 5. SPIE (2018)

39. Flesia, C., Korb, C.L.: Theory of the double-edge molecular technique for Doppler lidar wind measurement. Appl. Opt. 38, 432-440 (1999). https://doi.org/10.1364/AO.38.000432

40. Korb, C.L., Gentry, B.M., Li, S.X., Flesia, C.: Theory of the double-edge technique for Doppler lidar wind measurement. Appl. Opt. 37, 3097 (1998). https://doi.org/10.1364/ao.37.003097

41. Korb, C.L., Gentry, B.M.: New Doppler lidar methods for atmospheric wind measurements: the edge technique. In: Conference on lasers and electro-optics, p. CWK3 (1990)

42. Whiteway, J.A., Komguem, L., Dickinson, C., Cook, C., Illnicki, M., Seabrook, J., Popovici, V., Duck, T.J., Davy, R., Taylor, P.A., Pathak, J., Fisher, D., Carswell, A.I., Daly, M., Hipkin, V., Zent, A.P., Hecht, M.H., Wood, S.E., Tamppari, L.K., Renno, N., Moores, J.E., Lemmon, M.T., Daerden, F., Smith, P.H.: Mars water-ice clouds and precipitation. Science 325, 68-70 (2009). https://doi.org/10.1126/science.1172344

43. Schotland, R.M., Sassen, K., Stone, R.: Observations by lidar of linear depolarization ratios for hydrometeors. J. Appl. Meteorol. 10, 1011-1017 (1971). https://doi.org/10.1175/15200450(1971)010\%3c1011:oblold\%3e2.0.co;2

44. Durand, Y., Chinal, E., Endemann, M., Meynart, R., Reitebuch, O., Treichel, R.: ALADIN airborne demonstrator: a Doppler Wind lidar to prepare ESA's ADM-Aeolus Explorer mission. In: SPIE Optics + Photonics, p. 62961D (2006)

45. Reitebuch, O., Lemmerz, C., Nagel, E., Paffrath, U., Durand, Y., Endemann, M., Fabre, F., Chaloupy, M.: The airborne demonstrator for the direct-detection doppler wind lidar ALADIN on ADM-Aeolus. Part I: instrument design and comparison to satellite instrument. J. Atmos. Ocean. Technol. 26, 2501-2515 (2009). https://doi.org/10.1175/2009jtecha1309.1

46. She, C.-Y., Yue, J., Yan, Z.-A., Hair, J.W., Guo, J.-J., Wu, S.-H., Liu, Z.-S.: Direct-detection Doppler wind measurements with a Cabannes-Mie lidar: a comparison between iodine vapor filter and Fabry-Perot interferometer methods. Appl. Opt. 46, 4434 (2007). https://doi.org/10.1364/AO.46.004434

47. McKay, J.A.: Assessment of a multibeam Fizeau wedge interferometer for Doppler wind lidar. Appl. Opt. 41, 1760 (2002). https ://doi.org/10.1364/ao.41.001760

48. McKay, J.A.: Modeling of direct detection Doppler wind lidar II The fringe imaging technique. Appl. Opt. 37, 6487 (1998). https ://doi.org/10.1364/ao.37.006487

49. Bruneau, D., Garnier, A., Hertzog, A., Porteneuve, J.: Windvelocity lidar measurements by use of a Mach-Zehnder interferometer, comparison with a Fabry-Perot interferometer. Appl. Opt. 43, 173 (2004). https://doi.org/10.1364/ao.43.000173
50. Liu, Z., Kobayashi, T.: Differential discrimination technique for incoherent doppler lidar to measure atmospheric wind and backscatter ratio. Opt. Rev. 3, 47-52 (1996). https://doi.org/10.1007/ s10043-996-0047-0

51. Chanin, M.L., Garnier, A., Hauchecorne, A., Porteneuve, J.: A Doppler lidar for measuring winds in the middle atmosphere. Geophys. Res. Lett. 16, 1273-1276 (1989). https://doi.org/10.1029/ GL016i011p01273

52. Korb, C.L., Gentry, B.M., Li, S.X.: Edge technique Doppler lidar wind measurements with high vertical resolution. Appl. Opt. (1997). https://doi.org/10.1364/AO.36.005976

53. Reitebuch, O.: Wind lidar for atmospheric research. In: Atmospheric physics, pp. 487-507 (2012)

54. Kim, D., Kwon, S., Cha, H., Kim, Y., Sunwoo, J.: A newly designed single etalon double edge Doppler wind lidar receiving optical system. Rev. Sci. Instrum. 79, 123111 (2008). https://doi. org/10.1063/1.3053338

55. Yoon, Y., Shim, J., Jang, D., Kim, J., Eo, Y., Rhee, F.: Transmission spectra of Fabry-Perot etalon filter for diverged input beams. IEEE Photonics Technol. Lett. 14, 1215-1317 (2002). https://doi. org/10.1109/LPT.2002.801062

56. Chuang, T., Burns, P., Walters, E.B., Wysocki, T., Deely, T., Losse, A., Le, K., Drumheller, B., Schum, T., Hart, M., Puffenburger, K., Ziegler, B., Hovis, F.: Space-based, multi-wavelength solid-state lasers for NASA's Cloud Aerosol Transport System for International Space Station (CATS-ISS). In: Clarkson, W.A. and Shori, R. (eds.) Proc. SPIE, Solid State Lasers XXII: Technology and Devices, p. 85990 N. International Society for Optics and Photonics (2013)

57. Numata, K., Yu, A.W., Jiao, H., Merritt, S.A., Micalizzi, F., Fahey, M.E., Camp, J.B., Krainak, M.A.: Laser system development for the LISA (Laser Interferometer Space Antenna) mission. In: Proc. SPIE, solid state lasers XXIII: technology and Devices, p. 108961H (2019)

58. Beck, J., Welch, T., Mitra, P., Reiff, K., Sun, X., Abshire, J.: A highly sensitive multi-element $\mathrm{HgCdTe}$ e-APD detector for IPDA lidar applications. J. Electron. Mater. 43, 2910-2977 (2014). https ://doi.org/10.1007/s11664-014-3164-8

59. Sun, X., Abshire, J., Beck, J., Mitra, P., Reiff, K., Yang, G.: $\mathrm{HgCdTe}$ avalanche photodiode detectors for airborne and spaceborne lidar at infrared wavelengths. Opt. Express 25, 1658916602 (2017)

60. Beck, J., Wan, C., Kinch, M., Robinson, J., Mitra, P., Scritchfield, R., Ma, F., Campbell, J.: The HgCdTe electron avalanche photodiode. J. Electron. Mater. 35, 1166-1173 (2006). https://doi. org/10.1007/s11664-006-0237-3

61. Sun, X., Abshire, J.B., Beck, J.D.: HgCdTe e-APD detector arrays with single photon sensitivity for space lidar applications. In: SPIE sensing technologies + applications, p. 91140K (2014)

62. Fields, R., Sun, X., Abshire, J.B., Beck, J., Rawlings, R.M., Sullivan, W., Hinkley, D.: A linear mode photon-counting (LMPC) detector array in a CubeSat to enable earth science LiDAR measurements. In: international geoscience and remote sensing symposium (IGARSS) (2015)

63. Sun, X., Abshire, J.B., Beck, J.D., Mitra, P., Reiff, K., Yang, G.: $\mathrm{HgCdTe}$ avalanche photodiode detectors for airborne and spaceborne lidar at infrared wavelengths. Opt. Express (2017). https:// doi.org/10.1364/oe.25.016589

64. Krainak, M.A., Stephen, M.A., Martino, A.J., Lancaster, R.S., Allan, G.R., Lunt, D.L.: Tunable solid-etalon filter for the ICESat/ GLAS $532 \mathrm{~nm}$ channel lidar receiver. In: IGARSS 2003. In: 2003 IEEE International Geoscience and Remote Sensing Symposium. Proceedings (IEEE Cat. No.03CH37477), pp. 3020-3022, IEEE

65. Hubbs, J.E., Sun, X., Abshire, J.B., Lauenstein, J.-M., Sullivan, W., Beck, J.: Evaluation of space radiation effects on $\mathrm{HgCdTe}$ avalanche photodiode arrays for Lidar applications. In: Fulop, 
G.F., Hanson, C.M., Norton, P.R., Andresen, B.F., and Miller, J.L. (eds.) Infrared technology and applications XLIV, p. 15, SPIE (2018)

66. Liu, J.: An assessment of the global, seasonal, and interannual spacecraft record of Martian climate in the thermal infrared. J. Geophys. Res. (2003). https://doi.org/10.1029/2002JE001921

67. McCleese, D.J., Schofield, J.T., Taylor, F.W., Calcutt, S.B., Foote, M.C., Kass, D.M., Leovy, C.B., Paige, D.A., Read, P.L., Zurek, R.W.: Mars climate sounder: an investigation of thermal and water vapor structure, dust and condensate distributions in the atmosphere, and energy balance of the polar regions. J. Geophys. Res. Planets 112, 2007 (2007). https://doi.org/10.1029/2006je002790

68. Kleinböhl, A., Schofield, J.T., Abdou, W.A., Irwin, P.G.J., de Kok, R.J.: A single-scattering approximation for infrared radiative transfer in limb geometry in the Martian atmosphere. J. Quant. Spectrosc. Radiat. Transf. 112, 1568-1580 (2011). https://doi. org/10.1016/j.jqsrt.2011.03.006

69. Kleinböhl, A., Friedson, A.J., Schofield, J.T.: Two-dimensional radiative transfer for the retrieval of limb emission measurements in the martian atmosphere. J. Quant. Spectrosc. Radiat. Transf. 197, 511-522 (2017). https://doi.org/10.1016/j.jqsrt.2016.07.009

70. Guzewich, S.D., Newman, C.E., Smith, M.D., Moores, J.E., Smith, C.L., Moore, C., Richardson, M.I., Kass, D., Kleinböhl, A., Mischna, M., Martín-Torres, F.J., Zorzano-Mier, M.P., Battalio, M.: The vertical dust profile over gale crater, Mars. J. Geophys. Res. Planets. 122, 2779-2792 (2017). https://doi. org/10.1002/2017je005420

71. Komguem, L., Whiteway, J.A., Dickinson, C., Daly, M., Lemmon, M.T.: Phoenix LIDAR measurements of Mars atmospheric dust. Icarus 223, 649-653 (2013). https://doi.org/10.1016/J.ICARU S.2013.01.020
72. Ackermann, J.: The extinction-to-backscatter ratio of tropospheric aerosol: a numerical study. J. Atmos. Ocean. Technol. 15, 10431050 (1998). https://doi.org/10.1175/1520-0426(1998)015\%3c104 3:TETBRO\%3e2.0.CO;2

73. Dickinson, C., Komguem, L., Whiteway, J.A., Illnicki, M., Popovici, V., Junkermann, W., Connolly, P., Hacker, J.: Lidar atmospheric measurements on Mars and Earth. Planet. Space Sci. 59, 942-951 (2011). https://doi.org/10.1016/j.pss.2010.03.004

74. Vaughan, M.A., Liu, Z., McGill, M.J., Hu, Y., Obland, M.D.: On the spectral dependence of backscatter from cirrus clouds: assessing CALIOP's $1064 \mathrm{~nm}$ calibration assumptions using cloud physics lidar measurements. J. Geophys. Res. Atmos. 115, 2010 (2010). https://doi.org/10.1029/2009jd013086

75. Born, M., Wolf, E.: Principles of optics: electromagnetic theory of propagation, interference and diffraction of light. Elsevier (2013)

76. Atherton, P.D., Reay, N.K., Ring, J., Hicks, T.R.: Tunable Fabry-Perot filters. Opt. Eng. 20, 206806 (1981). https://doi. org/10.1117/12.7972819

77. Sloggett, G.J.: Fringe broadening in Fabry-Perot interferometers. Appl. Opt. 23, 2427-2432 (1984). https://doi.org/10.1364/ ao.23.002427

78. Measures, R.M.: Laser remote sensing : fundamentals and applications. Wiley, Hoboken (1984)

Publisher's Note Springer Nature remains neutral with regard to jurisdictional claims in published maps and institutional affiliations. 